\title{
Mental health interventions following COVID-19 and other coronavirus infections: a systematic review of current recommendations and meta-analysis of randomized controlled trials
}

Rodolfo F. Damiano, ${ }^{1}$ iD Talita Di Santi, ${ }^{1}$ Scott Beach, ${ }^{2,3}$ Pedro M. Pan, ${ }^{4}$ iD Alessandra L. Lucchetti, ${ }^{5}$ Felicia A. Smith, ${ }^{2,3}$ Orestes V. Forlenza, ${ }^{1}$ Gregory L. Fricchione, ${ }^{2,3}$ Eurípedes C. Miguel, ${ }^{1}$ Giancarlo Lucchetti ${ }^{5}$ iD

${ }^{1}$ Departamento de Psiquiatria, Instituto de Psiquiatria, Hospital das Clínicas, Faculdade de Medicina, Universidade de São Paulo, São Paulo, SP, Brazil. ${ }^{2}$ Department of Psychiatry, Massachusetts General Hospital, Boston, MA, United States. ${ }^{3}$ Department of Psychiatry, Harvard Medical School, Boston, MA, United States. ${ }^{4}$ Departamento de Psiquiatria, Universidade Federal de São Paulo, São Paulo, SP, Brazil.

${ }^{5}$ Departamento de Medicina, Faculdade de Medicina, Universidade Federal de Juiz de Fora, Juiz de Fora, MG, Brazil.

\begin{abstract}
Objective: To review the most common mental health strategies aimed at alleviating and/or preventing mental health problems in individuals during the coronavirus disease 2019 (COVID-19) and other coronavirus pandemics.

Methods: We conducted a systematic review of the literature assessing three databases (PubMed, SCOPUS, and PsycINFO). A meta-analysis was performed with data from randomized controlled trials (RCTs). For non-RCT studies, a critical description of recommendations was performed.

Results: From a total of 2,825 articles, 125 were included. Of those, three RCTs were included in the meta-analysis. The meta-analysis revealed that the interventions promoted better overall mental health outcomes as compared to control groups (standardized mean difference [SMD] $=0.87[95 \% \mathrm{Cl}$ $\left.0.33-1.41], \mathrm{p}<0.001, \mathrm{I}^{2}=69.2 \%\right)$, but did not specifically improve anxiety $(\mathrm{SMD}=0.98[95 \% \mathrm{Cl}-0.17$ to 2.13], $p>0.05 ; I^{2}=36.8 \%$ ). Concerning the systematic review, we found a large body of scientific literature proposing recommendations involving psychological/psychiatric interventions, self-care, education, governmental programs, and the use of technology and media.

Conclusions: We found a large body of expert recommendations that may help health practitioners, institutional and governmental leaders, and the general population cope with mental health issues during a pandemic or a crisis period. However, most articles had a low level of evidence, stressing the need for more studies with better design (especially RCTs) investigating potential mental health interventions during COVID-19.
\end{abstract}

PROSPERO registration: CRD42020190212.

Keywords: Community mental health; prevention; management; coronavirus; COVID-19; pandemic

\section{Introduction}

Pandemics have historically been more destructive and devastating in terms of morbidity and mortality than any other type of world disaster, rivaled only by human-made disasters of war and genocidal murder. Nevertheless, empirical data on mental health impacts of pandemics has been meager in comparison to what has been reported for natural or human-made disasters. Though disasterrelated mental health research has increased in recent years, most pandemics in the last century have generated limited study. ${ }^{1}$

Correspondence: Rodolfo F. Damiano, Departamento de Psiquiatria, Instituto de Psiquiatria, Hospital das Clínicas, Faculdade de Medicina, Universidade de São Paulo, Rua Dr. Ovídio Pires de Campos, 785, Cerqueira César, CEP 05403-903, São Paulo, SP, Brazil.

E-mail: damianorf@gmail.com

Submitted Oct 20 2020, accepted Dec 07 2020, Epub Apr 122021.
In early March 2020, the World Health Organization (WHO) declared the coronavirus disease 2019 (COVID19) outbreak a pandemic with unpredictable consequences. ${ }^{2}$ Almost 1 year later, more than 112 million individuals have been infected, with almost 2.5 million deaths worldwide caused by the new severe acute respiratory syndrome coronavirus 2 (SARS-CoV-2) virus. ${ }^{3}$ Furthermore, even though COVID-19 was initially described mainly as a respiratory disease, accumulating evidence suggests that several other systems are affected, and neuropsychiatric complications may play an important role in the overall disease burden. ${ }^{4,5}$

How to cite this article: Damiano RF, Di Santi T, Beach S, Pan PM, Lucchetti AL, Smith FA, et al. Mental health interventions following COVID-19 and other coronavirus infections: a systematic review of current recommendations and meta-analysis of randomized controlled trials. Braz J Psychiatry. 2021;43:665-678. http://dx.doi.org/ 10.1590/1516-4446-2020-1582 
A recent meta-analysis has shown that, similar to other coronaviruses (severe acute respiratory syndrome coronavirus 1 [SARS-CoV-1] and Middle East respiratory syndrome [MERS]), SARS-CoV-2 may affect the central nervous system (CNS) in many different ways, including acute, subacute, and chronic neurological and psychiatric impairments. ${ }^{6}$ Many acute neuropsychiatric events have been described, such as encephalopathy, delirium, anosmia, and ageusia ${ }^{7}$; the former two presumably relate to systemic/indirect insults to the brain, whereas the latter may reflect a specific mechanism through which the virus would directly affect nerve cells and/or damage support cells in the neuroepithelium. ${ }^{8-11}$ Higher rates of depression, anxiety, suicidal behavior, and post-traumatic stress disorder (PTSD) have been associated with prior viral pandemics including SARS and MERS, suggesting similar patterns may emerge with COVID-19., ${ }^{6,12,13}$ A recent study ${ }^{14}$ investigating a clinical sample of COVID-19 survivors 1-month after hospital discharge reported high rates of mental health symptoms, such as depression, anxiety, PTSD, insomnia, and obsessive-compulsive symptoms, which were directly related to baseline immune inflammation of exposed individuals during hospitalization. ${ }^{14}$

There are several processes through which a coronavirus can cause neuropsychiatric diseases. Potential neuropathological mechanisms include acute injury to nasal and gustative cells with trans-synaptic flow into the brain, as well direct viral injury to brain tissue via bloodbrain barrier (BBB) diapedesis, which generates a glial neuroinflammatory response. Even without viral transfer into the brain itself, there may be indirect CNS effects when cytokine storm results from breaches in the BBB, particularly via fenestrated endothelium and endotheliitis. This neuroinflammatory cascade can promote a hypercoagulability state leading to CNS thrombotic events and further injury to the BBB. ${ }^{6,7,15}$ Moreover, there are also possible environmental reasons for psychiatric morbidity. For example, individuals may develop stress due to social isolation, loneliness, economic burden, and unemployment following the pandemic, stigma, and several others. ${ }^{16-22}$

Given the fact that more than 20 million individuals have been infected, many of whom will develop psychiatric symptoms, it is possible that we might face a wave of neuropsychiatric diseases in the upcoming months and years. ${ }^{7}$ Within this context, experts around the world have proposed preventive and therapeutic strategies to manage mental health sequelae, largely based on their personal experiences and on the knowledge derived from other pandemics. ${ }^{23-26}$

Understanding the current evidence obtained through randomized controlled trials (RCTs) is crucial to guide mental health and other health practitioners. Likewise, understanding the opinions of mental health experts could potentially help in the development of future guidelines and in the design of clinical trials in order to minimize the mental health burden in this and future pandemic crises. However, at the present moment, there is a lack of systematic evidence and a scarcity of evidence-based practice recommendations regarding mental health preventive and management strategies in the COVID-19 pandemic, both individually and at a population level. Such evidence could possibly guide clinicians and health managers worldwide, helping to mitigate the mental health consequences of this and other pandemics.

Thus, the goal of this study was to review the current scientific literature regarding the most common mental health strategies available with the aim of alleviating and/ or preventing mental health problems (e.g., depression, anxiety, PTSD, and suicidal behavior) in individuals during COVID-19 and other coronaviruses pandemics. Moreover, we investigated the possible effectiveness of mental health interventions, as compared to control groups, based on a meta-analysis of randomized controlled clinical trials.

\section{Methods}

The present study was based on Preferred Reporting Items for Systematic Reviews and Meta-Analyses (PRISMA) recommendations ${ }^{27,28} \mathrm{~A}$ meta-analysis was performed with RCT results, and for non-RCT studies a critical description of recommendations was performed with all included articles. The study was registered on the PROSPERO ${ }^{29}$ platform under registration CRD42020190212.

\section{Eligibility criteria}

The following criteria were applied for inclusion of studies in this review: articles addressing preventive and/or management strategies to handle mental health issues in laypersons and health professionals during the COVID19, SARS, or MERS pandemics. For the meta-analysis, only RCTs reporting effect sizes and/or full data on means, standard deviations (SD), and sample sizes for each group were included; whereas for the descriptive analysis, all articles (letters to the editor, editorials, opinion essays, guidelines, observational studies) were included. No language or date restrictions were applied.

Exclusion criteria were non-coronavirus-related articles and articles that did not describe interventions or provide recommendations for the prevention or management of mental health concerns.

\section{Search strategy}

The literature search was conducted in three databases (PubMed, SCOPUS, and PsycINFO) from inception to June 3, 2020. Moreover, a hand search was performed on three pre-print databases (medRxiv, bioRxiv, PsyArXiv) in order to find additional articles. Key words were derived from meetings of the researchers and based on literature reviews, including a recent literature review on the prevalence of mental health problems due to COVID-19 infections. ${ }^{6}$ Keywords were grouped using the following Boolean operators and adjusted according to each database: "(mania OR manic OR dysthymia OR dysthymic OR anxiety OR anxious OR suicidal OR euphoria OR suicide OR affective OR depression OR depressive OR bipolar OR post-traumatic stress disorder OR PTSD OR mood OR mental health) AND (covid-19 OR coronavirus OR SARS-Cov-2 OR SARS OR MERS OR severe 
acute respiratory syndrome OR SARS-Cov OR middle east respiratory syndrome)."

\section{Study selection}

The selection of studies was conducted in three stages.

\section{Stage 1}

Two independent authors (RFD and TDS) screened simultaneously all references in the three databases using the search strategies described earlier. Duplicates were excluded using the Endnote software. Both authors determined eligibility based on title and/or abstract. Any article suggesting or recommending mental health interventions or presenting original data regarding any kind of interventions that might help mental health practitioners, governmental leaders, and educators around the world deal with the emergent mental health crisis were considered and included. Any disagreements between researchers were discussed with a third party (GL), and a final decision was made. All included articles on stage 1 were available to stage 2 .

\section{Stage 2}

The selected articles were read in full by the same independent researchers (RFD and TDS). Both authors independently analyzed the data focusing on the eligibility criteria and extracted the following variables: authors, first author, year of publication, journal, language, type of study, type of intervention (preventive or management), targeted population (health care workers, laypersons, etc.), and category of recommendation. Articles that did not meet eligibility criteria in stage 2 were excluded. In the descriptive analysis, the authors grouped the most common mental health interventions and recommendations and, based on this information, they determined the following groups: psychological/psychiatric interventions, complementary and alternative therapies, self-care, technology and media, education, governmental programs, general recommendations, spirituality and religiousness, health care institutions, and physical intervention. Each article could have more than one category of recommendation, and any disagreement between researchers was again discussed with a third party (GL).

\section{Stage 3}

All information was compiled, and an expert summary provided. RCTs meeting the inclusion criteria were included for meta-analysis. Practical recommendations for laypersons, mental health care workers, and agencies were summarized.

\section{Quality assessment}

Each RCT was assessed using the Cochrane Back Review Group Criteria List for Methodological Quality Assessment ${ }^{30}$ by two independent authors (RFD and TDS). This assessment covers the following methodological items: $\mathrm{A}=$ randomization method; $\mathrm{B}=$ allocation concealed; $\mathrm{C}=$ similar baseline; $\mathrm{D}=$ patient blinded; $\mathrm{E}=$ provider blinded; $\mathrm{F}$ = assessor blinded; $\mathrm{G}=$ cointervention avoided; $\mathrm{H}=$ acceptable compliance; $\mathrm{I}=$ acceptable drop out; $\mathrm{J}=$ timing of outcome of assessment similar; and $\mathrm{K}=$ intention to treat analysis. A score ranging from 0 to 11 was used.

\section{Meta-analysis}

The software Meta-Essentials was employed for the meta-analysis. All outcomes provided by each article were included. For studies that had more than one outcome group (e.g., anxiety, depression, somatization), analyses were carried out separately for each group, with studies labeled with a letter in parentheses (e.g., "b") for each of these comparisons.

Effect size was based on the mean, SD and sample size of the intervention and control groups for each comparison. For the meta-analyses that compiled different scales, effect size was calculated as the standardized mean difference $(S M D=$ Cohen $d)$ with its $95 \%$ confidence interval $(95 \% \mathrm{Cl})$. This approach enabled inclusion of different outcome measures in the same synthesis.

Random effects model meta-analyses were conducted for all studies that had full data assessing mental health in general, and a sub-analysis was carried out for anxiety. A $p$-value $<0.05$ was adopted as significant and heterogeneity was determined using $\mathrm{I}^{2}$.

\section{Results}

Figure 1 summarizes the steps of the systematic review. We found 2,825 articles through database searching: 877 from PubMed, 1,562 from EMBASE, and 386 from Psyc INFO. No other studies were found in additional databases (i.e., medRxiv, bioRxiv, PsyArXiv). After excluding duplicates, a total of 2,070 articles remained for the first screening. From those, 13 were automatically excluded due to the lack of title.

From 2,057 references screened, 154 were accepted for full-text reading. After full-text reading, 29 additional articles were excluded, leaving a total of 125 articles that were included in the final analysis. Of these, four were RCTs. ${ }^{31-34}$ However, only three were included in the metaanalysis, ${ }^{32-34}$ because one provided only absolute numbers and percentages rather than means and standard deviation. ${ }^{31}$

\section{Descriptive analysis of the articles included in the systematic review}

A total of 125 articles published from 2003 (first article) to 2020 regarding mental health interventions for COVID-19 and other coronaviruses (SARS and MERS) were found.

Table 1 summarizes our results. More than $90 \%$ of the articles were published in 2020 and were about COVID19 , while the remaining minority included SARS-CoV-1 $(6.4 \%)$, MERS $(0.8 \%)$, and more than one coronavirus $(0.8 \%)$. The majority of studies were conducted in China (28.8\%), the United States (14.4\%), and the United Kingdom $(12 \%)$, followed by Italy $(5.6 \%)$, India $(4.8 \%)$, and 

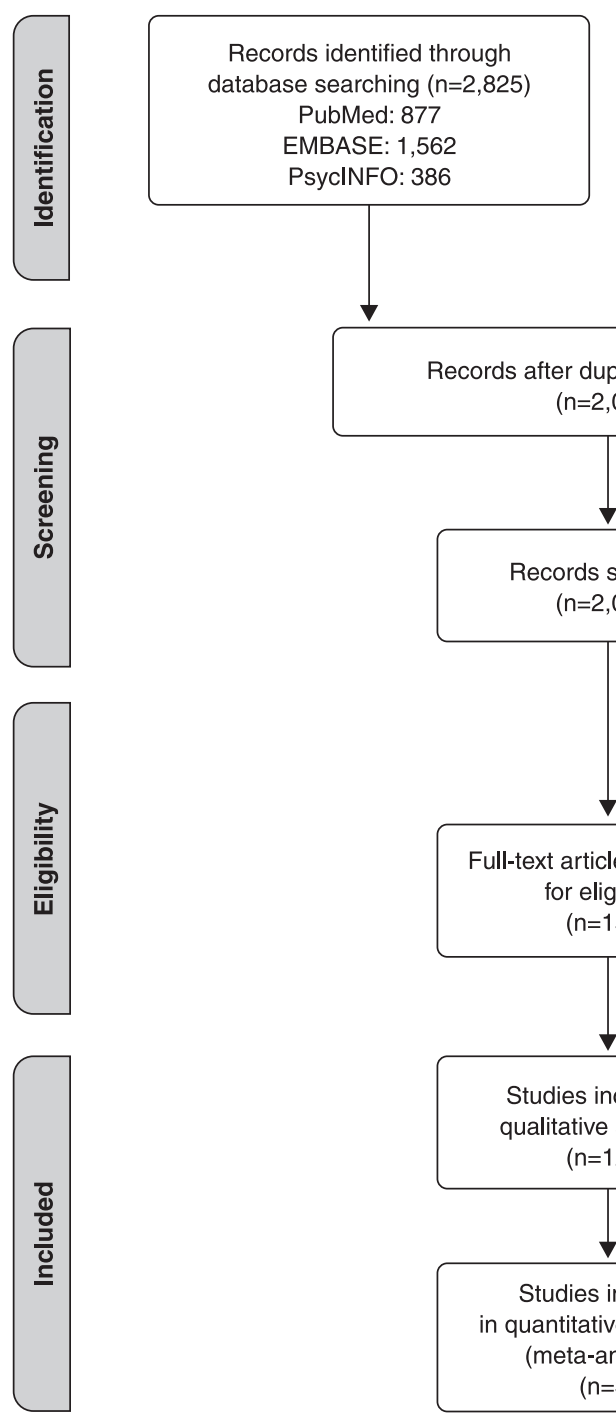

Additional experimental articles identified through other sources (medRxiv, bioRxiv, PsyArXiv)

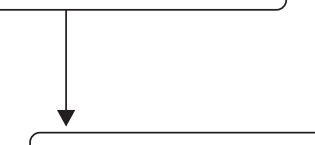

$$
(\mathrm{n}=0)
$$
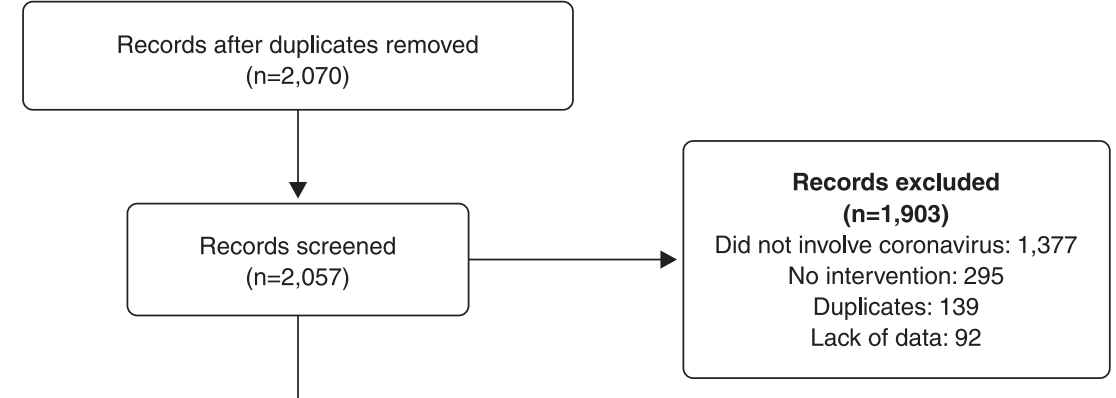

Studies included in qualitative synthesis $(n=125)$

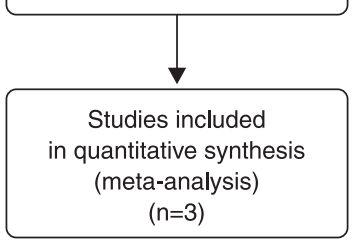

Full-text articles excluded, with reasons $(n=29)$

Did not involve coronavirus: 3 No intervention: 17 Duplicates: 1 Lack of data: 8

Figure 1 Preferred Reporting Items for Systematic Reviews and Meta-Analyses (PRISMA) flow diagram.

Australia (3.2\%). Most of these publications were letters to the editors $(33.6 \%)$ and review articles $(28 \%)$, followed by original research articles, largely cross-sectional in design (9.6\%). The remaining articles $(28.8 \%)$ included editorials, reports, experimental studies, cohort studies, consensus statements, meta-analyses, opinion, and quasi-experimental studies. Almost $70 \%$ included recommendations for the lay public and $20.8 \%$ for health care professionals.

\section{Mental health interventions}

Table 2 summarizes the descriptive analysis of the 125 articles addressing preventive or interventional strategies for mental health symptoms in individuals during coronavirus pandemics. Recommendations regarding any kind of preventive and/or management interventions were made by 86.4 and $58.4 \%$ of all included articles respectively. More than one intervention was proposed in $69.6 \%$ of these articles, with $21.6 \%$ proposing more than five different interventions. The most common combined interventions were psychological and psychiatric (12.8\%), technology and media (7.2\%), and the combination of both $(6.4 \%)$. Regarding each intervention, psychiatric and psychological were the most frequently reported, followed by self-care and educational interventions.

\section{Meta-analysis}

For the meta-analysis, three RCTs were included, ${ }^{32-34}$ for a total of 128 participants. The meta-analysis revealed improved mental health in intervention groups as compared to control groups for a combination of outcomes analyzed together (improved anxiety, ${ }^{32-34}$ depressive symptoms, ${ }^{33,34}$ sleep quality, ${ }^{32}$ hostility, ${ }^{33}$ and somatization $\left.^{33}\right)\left(\mathrm{SMD}=0.87\right.$ [95\%Cl 0.33-1.41], $\mathrm{p}<0.001, \mathrm{l}^{2}=$ $69.2 \%$ ) (three studies included, with eight comparisons) (Figure 2). Due to the limited number of studies, an individual meta-analysis was only possible for anxiety, 
Table 1 Descriptive analysis of articles proposing mental health interventions for COVID-19 and other coronaviruses

\begin{tabular}{|c|c|}
\hline & No. articles (\%) \\
\hline $\begin{array}{l}\text { Year } \\
2020^{12,25,31,32,34,35-145} \\
2003-2019^{33,146-153}\end{array}$ & $\begin{array}{c}116(92.8) \\
9(7.2)\end{array}$ \\
\hline $\begin{array}{l}\text { Journal } \\
\text { Asian Journal of Psychiatry } 38,64,71,75,81,97,106,109,114,119,125 \\
\text { Lancet Psychiatry }{ }^{12,55,67,73,88,95,140} \\
\text { Psychiatry Research }{ }^{47,83,104,116,126,141,144} \\
\text { Clinical Neuropsychiatry } \\
\text { Other }\end{array}$ & $\begin{aligned} 11 & (8.8) \\
7 & (5.6) \\
7 & (5.6) \\
4 & (3.2) \\
96 & (76.8)\end{aligned}$ \\
\hline 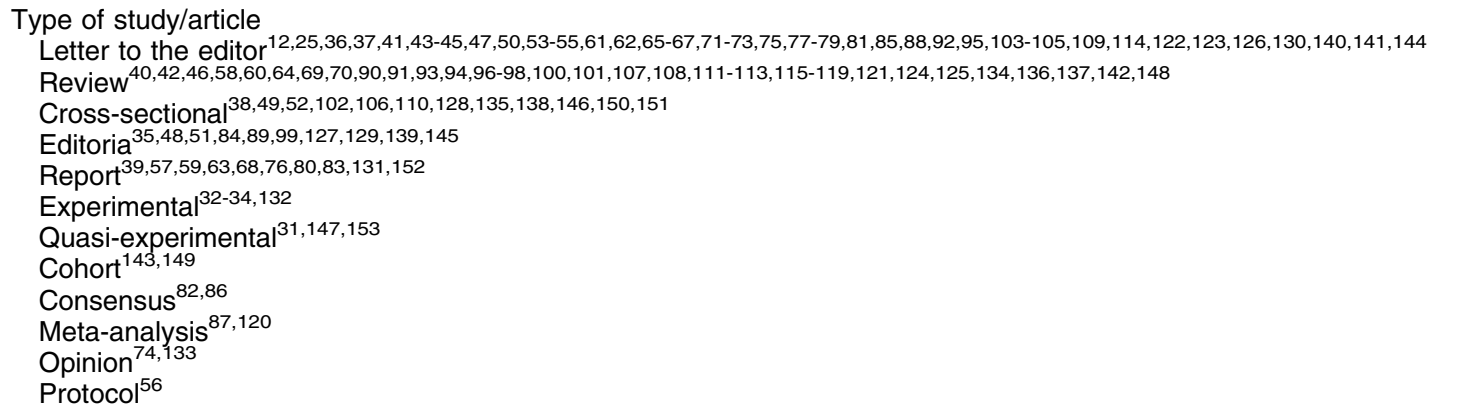 & $\begin{array}{c}42(33.6) \\
35(28.0) \\
12(9.6) \\
10(8.0) \\
10(8.0) \\
4(3.2) \\
3(2.4) \\
2(1.6) \\
2(1.6) \\
2(1.6) \\
2(1.6) \\
1(0.8)\end{array}$ \\
\hline $\begin{array}{l}\text { Country of the corresponding author } \\
\text { China }^{32-34,38,43,47,52,55-57,67,77,78,80,83,92-95,120,125-127,132,134-136,138,142-144,148-151,153} \\
\text { United States }{ }^{25,39,50,51,54,69,79,86,91,101,107,108,114,121,123,124,140,141} \\
\text { United Kingdom } 12,42,48,49,59,62,70,73,74,89,96,102,122,129,137 \\
\text { Italy }{ }^{53,63,65,99,112,116,139} \\
\text { India }^{64,71,75,97,98,119} \\
\text { Australia } \\
\text { Others }\end{array}$ & $\begin{aligned} 36 & (28.8) \\
18 & (14.4) \\
15 & (12.0) \\
7 & (5.6) \\
6 & (4.8) \\
4 & (3.2) \\
39 & (31.2)\end{aligned}$ \\
\hline $\begin{array}{l}\text { Coronavirus } \\
\text { SARS-Cov-2 } 2^{12,25,31,32,34-57,59-145} \\
\text { SARS-Cov-1 } \\
\text { MERS }{ }^{352} \text {.146-151,153 } \\
\text { More than one coronavirus }\end{array}$ & $\begin{array}{l}115(92.0) \\
8(6.4) \\
1(0.8) \\
1(0.8)\end{array}$ \\
\hline $\begin{array}{l}\text { Population included or targeted for recommendations } \\
\text { General population }{ }^{12,25,31,32-38,44-47,50,51,53,54,58,60-71,73,75,76,78-81,84-86,88-95,97,98,100-112,114,116-120,125-128,130,131,140-145,148-153} \\
\text { Health care workers }{ }^{39,41-43,48,49,52,55,57,59,72,74,87,96,121,122,124,132,133,135-139,146,147} \\
\text { General population and health care workers }{ }^{40,77,82,83,99,113,115,123,129,134} \\
\text { Children/adolescents }{ }^{56}\end{array}$ & $\begin{array}{l}88(70.4) \\
26(20.8) \\
10(8.0) \\
1(0.8)\end{array}$ \\
\hline
\end{tabular}

COVID-19 = coronavirus disease 2019; MERS = Middle East respiratory syndrome; SARS-CoV = severe acute respiratory syndrome coronavirus.

without any differences detected between the intervention and control groups $(\mathrm{SMD}=0.98[95 \% \mathrm{Cl}-0.17$ to 2.13$]$, $p>0.05 ; l^{2}=36.8 \%$ ) (three studies included, with three comparisons). Other comparisons were not possible due to the lack of data.

Moreover, a quality assessment of clinical trials was carried out for the three included articles (Table 3). In general, the articles were of low quality, with a general score ranging from 3 to 7 (Table 1).

The first clinical trial was a 2006 study of a 1-day group debriefing technique, Strength-Focused and MeaningOriented Approach for Resilience and Transformation (SMART), based on Asian philosophies and traditional Chinese medicine ${ }^{33}$ applied for people with chronic diseases 1 month after the SARS pandemic. The authors found that the intervention group reported improved depressive symptoms, but no difference was detected in anxiety, hostility, and somatization symptoms. Two other intervention studies were administered to patients with COVID-19. Liu et al. ${ }^{32}$ evaluated the effects of progressive muscle relaxation, $30 \mathrm{~min}$ daily for 5 days, for patients with COVID-19 in an isolation ward. Subjects who received the intervention improved significantly in anxiety and sleep quality measures. Another Chinese group investigated the impact of an internet-based intervention for depressive and anxiety symptoms in COVID-19 patients. ${ }^{34}$ This 2-week trial consisted of daily 50-minute practices of breath relaxation techniques, mindfulness, "refuge skill," and a "butterfly hug." The authors found a significant improvement in mild depressive symptoms and anxiety symptoms after the 1st and 2nd weeks of the intervention. 
Table 2 Mental health interventions for COVID-19 and other coronaviruses proposed by articles included in the systematic review

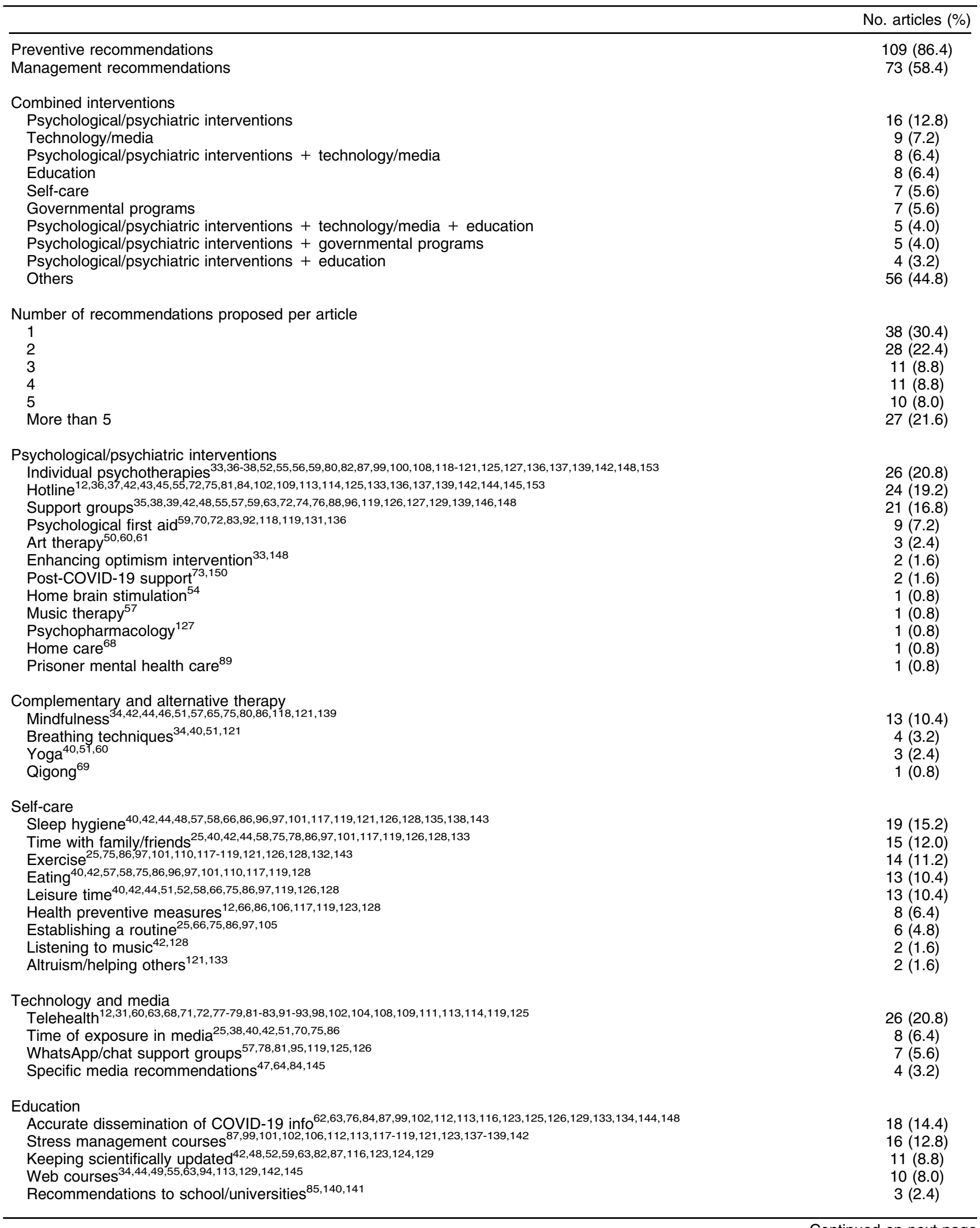


No. articles (\%)

\begin{tabular}{|c|c|}
\hline \multicolumn{2}{|l|}{ Governmental programs } \\
\hline Social and economic support ${ }^{12,25,64,67,76,88,90,92,96,99,103,117,119,127,133,135,148,150,151}$ & $19(15.2)$ \\
\hline Increased mental health services ${ }^{12,25,41,43,53,64,65,67,76,82,92,99,107,127,136,148,152}$ & $17(13.6)$ \\
\hline Supporting victims of domestic violence ${ }^{12,25,107,113}$ & $4(3.2)$ \\
\hline \multicolumn{2}{|l|}{ General recommendations } \\
\hline Avoid the term "social distancing"90,99,101,130 & $4(3.2)$ \\
\hline Clinical tips ${ }^{70,77,90,93}$ & $4(3.2)$ \\
\hline \multicolumn{2}{|l|}{ Spirituality and religiousness } \\
\hline Pray $^{42,128}$ & $2(1.6)$ \\
\hline Religious practices ${ }^{94}$ & $1(0.8)$ \\
\hline \multicolumn{2}{|l|}{ Health care institutions } \\
\hline Safe environment/protective equipment ${ }^{12,42,48,52,59,76,82,87,96,121,122,124,147}$ & $13(10.4)$ \\
\hline Balanced shift rotations ${ }^{12,42,48,76,82,87,96,122,129}$ & $9(7.2)$ \\
\hline Place to rest ${ }^{42,48,76,87,96,122,124}$ & $7(5.6)$ \\
\hline Avoiding moral injury ${ }^{74,89,122,129}$ & $4(3.2)$ \\
\hline Role models ${ }^{48,122}$ & $2(1.6)$ \\
\hline Provide housing 96,124 & $2(1.6)$ \\
\hline \multicolumn{2}{|l|}{ Physical intervention } \\
\hline Muscle relaxation ${ }^{32}$ & $1(0.8)$ \\
\hline
\end{tabular}

COVID-19 = coronavirus disease 2019.

\begin{tabular}{|c|c|c|c|c|c|c|c|c|c|c|c|c|}
\hline Study name & Cohen $d$ & $95 \% \mathrm{Cl}$ & Weight & -1.00 & -0.50 & 0 & 0.50 & 1.00 & 1.50 & 2.00 & 2.50 & 3.00 \\
\hline Liu (a) 2020 & 1.08 & 0.48 to 1.68 & 0.14 & & & & $\vdash$ & & & & & \\
\hline Liu (b) 2020 & 1.84 & 1.17 to 2.51 & 0.13 & & & & & & 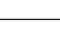 & & $\longrightarrow$ & \\
\hline $\mathrm{Ng}$ (a) 2006 & 0.49 & -0.24 to 1.22 & 0.13 & & & & 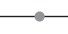 & & & & & \\
\hline $\mathrm{Ng}$ (b) 2006 & 0.80 & 0.05 to 1.55 & 0.12 & & & & & & $\longrightarrow$ & & & \\
\hline $\mathrm{Ng}$ (c) 2006 & 0.04 & -0.67 to 0.76 & 0.13 & & & & & & & & & \\
\hline $\mathrm{Ng}$ (d) 2006 & 0.09 & -0.63 to 0.81 & 0.13 & & & & & & & & & \\
\hline Wei (a) 2020 & 1.21 & 0.33 to 2.09 & 0.11 & & & & & & & 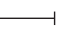 & & \\
\hline Wei (b) 2020 & 1.46 & 0.55 to 2.37 & 0.11 & & & & & & & & & \\
\hline Pooled & 0.87 & 0.33 to 1.41 & & & & & & & & & & \\
\hline
\end{tabular}

Figure 2 Meta-analysis of mental health intervention for coronavirus disease 2019 (COVID-19) and other coronaviruses. Pooled effect size: Cohen $d=0.87$ (95\% confidence interval $[95 \% \mathrm{Cl}] 0.33-1.41), p<0.001, \mathrm{I}^{2}=69.2 \%$. Liu ${ }^{32}(\mathrm{a})=$ anxiety; $\mathrm{Liu}^{32}$ (b) = sleep quality; $\mathrm{Ng}^{33}(\mathrm{a})=$ anxiety; $\mathrm{Ng}^{33}$ (b) = depression; $\mathrm{Ng}^{33}$ (c) = somatization; $\mathrm{Ng}^{33}$ (d) = hostility; Wei ${ }^{34}$ (a) = depression; Wei ${ }^{34}$ (b) = anxiety.

\section{Discussion and clinical recommendations}

To the best of our knowledge, this is the first study to systematically evaluate interventions designed to improve mental health outcomes during and after coronaviruses infections. In the meta-analysis, interventions were effective in improving the general mental health outcomes (anxiety, depressive symptoms, sleep problems, hostility, and somatization) of individuals, but only when aggregated. When analyzing interventions for impact specifically on anxiety symptoms, the results were not significant.

Concerning the descriptive systematic review, we found a large body of scientific literature proposing mental health interventions, mostly based on low-quality levels of evidence (i.e., expert opinions or cross-sectional studies). Most articles were from China and the United States and focused on the novel SARS-CoV-2 infection. Below, we will discuss the most important findings from these studies for each intervention group, as well as propose future interventions for mental health practitioners, general clinicians, educators, and governmental leaders.

\section{Psychological/psychiatric interventions}

Psychiatric and psychological interventions were, by far, the most common strategies recommended. Most recommendations were aimed at preventing the development of PTSD, ${ }^{154-156}$ given the increased risk of PTSD reported in other coronaviruses ${ }^{6}$ and the $\mathrm{H} 1 \mathrm{~N} 1$ epidemic. ${ }^{157}$ Notably, most experts recommended individual psychotherapies, ${ }^{55,87}$ but also stressed the importance of hotlines ${ }^{24,158}$ and peer support groups. ${ }^{59,148}$ Certain individual interventions have more evidence for people facing acute stress, ${ }^{159,160}$ such as Trauma-Focused Cognitive Behavioral 
Table 3 Quality assessment of controlled randomized trials

\begin{tabular}{lllllllllllllll}
\hline Author & $\mathrm{n}$ & $\mathrm{A}$ & $\mathrm{B}$ & $\mathrm{C}$ & $\mathrm{D}$ & $\mathrm{E}$ & $\mathrm{F}$ & $\mathrm{G}$ & $\mathrm{H}$ & $\mathrm{I}$ & $\mathrm{J}$ & $\mathrm{K}$ & Total \\
\hline $\mathrm{Ng}^{33}$ & 51 & - & + & + & - & - & - & $?$ & $?$ & + & + & $?$ \\
$\mathrm{Liu}^{32}$ & 51 & $?$ & $?$ & + & - & - & - & $?$ & $?$ & + & + & $?$ \\
$\mathrm{Wei}^{34}$ & 26 & + & + & + & $?$ & $?$ & $?$ & + & + & + & + & $?$ & 7 \\
\hline
\end{tabular}

$\mathrm{n}=$ number of participants; $\mathrm{A}=$ randomization method; $\mathrm{B}=$ allocation concealed;

$\mathrm{C}=$ similar baseline; $\mathrm{D}=$ patient blinded; $\mathrm{E}$ = provider blinded; $\mathrm{F}=$ assessor blinded;

$\mathrm{G}=$ cointervention avoided; $\mathrm{H}=$ acceptable compliance; $\mathrm{I}=$ acceptable drop out;

$\mathrm{J}=$ timing of outcome of assessment similar and; $\mathrm{K}=$ intention to treat analysis.

+ indicates information provided; - indicates information not provided; ? indicates not possible to determine.

Therapy ${ }^{161}$ and Prolonged Exposure Therapy. ${ }^{162,163}$ Psychological First Aid (i.e., initial crisis interventions with the aim to stabilize survivors from disasters) is a subset of interventions that requires more investigation. $\mathrm{Ng}$ et al. $^{33}$ found a negative association of a debriefing technique with depressive symptoms 1 month after stress exposure. However, several other studies and expert consensus guidelines suggest that debriefing interventions following an acute stressor may be contraindicated, highlighting a greater risk of developing PTSD. ${ }^{164}$

Early psychopharmacological interventions were also recommended in some articles. ${ }^{127}$ While there is a lack of studies investigating pharmacological interventions specifically for acute stress, ${ }^{160}$ it is important to underscore the importance of avoiding iatrogenic contributors. For example, several studies have pointed out an increase of PTSD symptoms following the use of benzodiazepines for acute stress. ${ }^{165,166}$ Thus, experts suggest that clinicians avoid using benzodiazepines to treat mild symptoms (e.g., mild anxiety, insomnia) of acute stress and adjustment disorders, ${ }^{167}$ but more studies should be done to investigate these controversies.

\section{Complementary and alternative therapies}

Meditation, especially mindfulness, ${ }^{34,46}$ yoga, ${ }^{40,51}$ and breathing techniques, ${ }^{34,121}$ were the most recommended complementary practices. There is a large body of evidence of the positive effects of these practices in mental health. ${ }^{168}$ Mindfulness meditation has been used and validated for acute stress situations, ${ }^{169}$ including those related to COVID-19. ${ }^{34}$ It has been shown to have an effect on mood and anxiety, inducing neurobiological changes, even after 8-week meditation programs. ${ }^{170,171}$ A recent systematic-review ${ }^{172}$ did highlight possible adverse effects from meditation practices and meditation-based therapies, however, such as the emergence of depressive and anxiety symptoms, cognitive anomalies, and suicidal behavior. Based on these studies, we suggest that complementary and alternative practices (especially mindfulness) should be encouraged as a good and low-cost practice to alleviate and/or prevent mental health issues following traumatic periods/experiences. However, attention should be paid especially to moderate and severe cases, where these practices could be detrimental if not enhanced with specialized mental health care.

\section{Self-care}

Engaging in self-care practices is essential in promoting positive mental health. Several authors have pointed out the importance of exercise, eating habits, leisure time, sleep hygiene, establishing a routine, reducing alcohol intake, and spending more time with family and friends. ${ }^{25,35}$ There is a large body of evidence that self-care behaviors can decrease the development of mental health issues and stimulate positive mental health in the general population, but also in in mental health practitioners. ${ }^{173-175}$ Interestingly, two authors stressed the importance of altruistic behaviors in promoting mental health. ${ }^{121,133}$ Previous articles have shown a positive relationship between altruistic behaviors and mental health outcomes, ${ }^{176}$ though a recent crosssectional study investigating the effect of altruism on mental health showed a negative relationship between high levels of altruism and negative affect during the COVID-19 pandemic. ${ }^{177}$ This finding was corroborated by a large population-based study, ${ }^{178}$ which can be explained due to the fact that highly altruistic people might engage less in self-care practices.

\section{Institutions}

It is critical that institutions provide a safe and healthy environment in order to foster personal growth and positive mental health outcomes among health care workers. Several experts recommended the importance of protecting health care workers from exposures to coronavirus, providing adequate personal protective equipment, setting balanced shift rotations, creating a comfortable place to rest, providing housing when needed, and providing positive role models for personal growth. ${ }^{74,124,129}$ We suggest that institutions and governments should pay attention to and stimulate self-care behaviors of their professionals in order to alleviate their distress and promote better mental health. Special attention should be paid to low- and middle-income countries (LMIC) countries, where health professionals have an extremely high workload and are underpaid. Considerations may include increasing wages, reducing workloads, and affording professionals time to engage in self-care activities. ${ }^{20}$

\section{Technology and media}

In the midst of the "technology era" in health care services, ${ }^{179}$ many online programs have been utilized to 
support mental health during the COVID-19 pandemic, and some of them may become standard practices once the pandemic ends. Telehealth services, ${ }^{145}$ including online psychological crisis intervention, ${ }^{142}$ telephone support services, ${ }^{102}$ online mental health services, ${ }^{95}$ television-based interventions, ${ }^{31}$ smartphone-based e-consults, ${ }^{71}$ and the use of social media for psychological interventions ${ }^{57}$ are some examples of successful programs developed this year. Leveraging such technologies has the potential to increase access to mental health care, create mentorship between mental health specialists and general practitioners in distant communities, and facilitate dissemination of general mental health recommendations.

Despite the important benefits of technology with regards to mental wellness, there are also some potential downsides. In LMICs, as well as for low-income individuals from developed nations, the lack of access to internet may create larger social and economic disparities. The increased exposure to internet and social media has already been associated with mental health issues, including decline in subjective well-being ${ }^{180}$ and increased depressive symptoms. ${ }^{181}$ Interestingly, Bessière et al., ${ }^{182}$ in a longitudinal study, found that using the internet for health purposes might be associated with increased depressive symptoms, while using it to communicate with family and friends might be associated with decreased symptoms of depression. The authors suggest that their results could be explained by an increase in rumination, unnecessary alarm, or over-attention to health problems. More studies are needed to explore the potential deleterious effects of telehealth and technology systems in psychiatric and psychological care. Mental health providers should be aware of these problems while evaluating individuals during pandemic situations.

\section{Educational}

The use of programs to educate laypersons and health care workers about stress management ${ }^{137}$ and to disseminate reliable and scientifically updated information about the disease ${ }^{63}$ might be an important strategy to reduce anxiety and increase self-confidence. Furthermore, the importance of maintaining online school and university classes and other web courses was also addressed by many experts ${ }^{49,141}$ and seems to be associated with a sense of well-being and accomplishment. However, some concerns emerge in low income countries and low-income areas of other countries, where citizens might face serious economic issues during critical periods, and might not have access to internet or electronic devices. ${ }^{183}$ Governments should work to increase access to the internet in low income and vulnerable populations, and mental health professionals are encouraged to develop educational programs for these patients.

\section{Governmental programs}

The negative mental health impact of economic crises ${ }^{19,184}$ and previous pandemic outbreaks ${ }^{6}$ has already been studied by many authors. It is crucial that during crises, government, especially from LMICs, ${ }^{64}$ lead initiatives to prevent and address mental health issues, including suicidal behavior, ${ }^{12}$ that might arise from distressing situations. Several mental health experts pointed out the importance of governments in lending social and economic support to individuals, ${ }^{119,151}$ increasing mental health services, ${ }^{53}$ and supporting victims of domestic violence. ${ }^{25}$ During the COVID-19 pandemic, countries have developed many different economic interventions in order to ameliorate its impact on health. ${ }^{185}$ More studies should be done to understand the exact impact of these initiatives in public health.

\section{Spirituality and religiousness}

There is a growing body of evidence highlighting the positive role of spirituality and religiousness in mental health. ${ }^{186,187}$ However, few experts recommended spiritual or religious practices as a possible coping mechanism during any coronavirus epidemic. Notably, several groups around the world are developing strategies to deal with the growing spiritual struggle that people might face during a crisis, such as the development of hotlines focused in promoting spiritual care and fulfill the lack of religious support during quarantine. ${ }^{158,188}$ However, more empirical studies should be done in order to investigate the exact impact of these religious/spiritual intervention strategies in mental health. Moreover, mental health providers should be aware of the spiritual needs of their patients, identifying if the use of religiousness and spirituality is functional or dysfunctional, and referring to religious leaders or chaplains if appropriate.

\section{Physical interventions}

Physical interventions, such as muscle relaxation techniques and yoga exercises, have also been reported by some experts as a tool to curtail anxiety and sleep disturbances during the COVID-19 pandemic. Liu et al. ${ }^{32}$ found a positive effect on both anxiety and sleep quality for patients with COVID-19. This finding is consistent with a previous study that used the same technique with pregnant women ${ }^{189}$ and breast cancer patients. ${ }^{190}$ The underlying mechanism might be the balance between the anterior and hypothalamic nucleus and the reduction of sympathetic nervous system activity, ${ }^{32}$ though further studies are needed.

\section{General recommendations}

Finally, several general recommendations with clinical tips for mental health practitioners were also published during the COVID-19 and other pandemics. ${ }^{90,93}$ Interestingly, many experts recommended the avoidance of the term "social distancing," preferring "physical distancing" in order to reduce feelings of rejection among psychiatric patients..$^{90,130}$ To our knowledge, no study has empirically investigated the effect of this recommendation in clinical practice.

\section{Limitations}

This study has several limitations. First, we only included three databases, and articles published in other 
databases might not have been included. Second, our search strategy is limited to only few mental health issues, potentially limiting generalization. Third, most articles included had a low level of evidence, with a great number of letters to the editor, opinions, editorials, recommendations, and case reports. Forth, due to the dynamic and continuous process of publications during COVID-19 pandemic, new articles may have been published in the months after this review. Fifth, our meta-analysis included only three articles, which could limit our findings. More RCTs are needed in order to overcome this limitation. Finally, we found a high heterogeneity among RCTs, including different intervention populations, different types of interventions, and different outcome measures. Such heterogeneity may have impacted the findings and interpretation of our meta-analysis.

\section{Conclusions}

The present review found that there are few clinical trials assessing the effectiveness of interventions to improve the mental health of individuals during coronavirus pandemics. Although the results were superior for the intervention groups as compared to the control groups for general mental health, these results relied on only three studies with limited quality. When analyzing individual outcomes, such as anxiety, the pooled results were not significant. However, in the systematic review, we found a large body of expert recommendations that can help health practitioners, institutional and governmental leaders, and laypersons cope with mental health issues during a pandemic, as well as during periods of social and economic crises. Furthermore, despite the low level of evidence, many of these recommendations can be generalized to routine daily practice in order to improve mental health and wellbeing. This is essential given that in many countries, and especially in developing countries, citizens will face years of social and economic adversity that will have a direct impact on the mental health of populations.

\section{Disclosure}

The authors report no conflicts of interest.

\section{References}

1 Morganstein JC, Fullerton CS, Ursano RJ, Donato D, Holloway HC Pandemics: health care emergencies In: Raphael B, Fullerton CS, Weisaeth L, Ursano RJ Textbook of disaster psychiatry. 2nd ed. Cambridge: Cambridge University Press; 2017, p.270-84.

2 Mahase E. Covid-19: WHO declares pandemic because of "alarming levels" of spread, severity, and inaction. Brit Med J. 2020;368: m1036.

3 Johns Hopkins University \& Medicine. Coronavirus resource center [Intenret]. coronavirus.jhu.edu/map.html. 2020 [cited 2020 May 20].

4 Helms J, Kremer S, Merdji H, Clere-Jehl R, Schenck M, Kummerlen $\mathrm{C}$, et al. Neurologic features in severe SARS-CoV-2 infection. New Eng J Med. 2020;382:2268-70.

5 Rajkumar RP. COVID-19 and mental health: a review of the existing literature. Asian J Psychiatr. 2020;52:102066.

6 Rogers JP, Chesney E, Oliver D, Pollak TA, McGuire P, Fusar-Poli $P$, et al. Psychiatric and neuropsychiatric presentations associated with severe coronavirus infections: a systematic review and meta-analysis with comparison to the COVID-19 pandemic. Lancet Psychiatry. 2020;7:611-27.

7 Troyer EA, Kohn JN, Hong S. Are we facing a crashing wave of neuropsychiatric sequelae of COVID-19? Neuropsychiatric symptoms and potential immunologic mechanisms. Brain Behav Immun, 202087:34-9.

8 Benameur K, Agarwal A, Auld S, Butters MP, Webster AS, Ozturk T, et al. Encephalopathy and encephalitis associated with cerebrospinal fluid cytokine alterations and coronavirus disease, Atlanta, Georgia, USA, 2020. Emerg Infect Dis. 2020;26: 2016-21.

9 Aghagoli G, Marin BG, Katchur NJ, Chaves-Sell F, Asaad WF, Murphy SA. Neurological involvement in COVID-19 and potential mechanisms: a review. Neurocrit Care 2020 Jul 13;1-10. doi: 10.1007/ s12028-020-01049-4. Online ahead of print.

10 Brann DH, Tsukahara T, Weinreb C, Lipovsek M, Van den Berge K, Gong B, et al. Non-neuronal expression of SARS-CoV-2 entry genes in the olfactory system suggests mechanisms underlying COVID-19-associated anosmia. Sci Adv. 2020;6:eabc5801.

11 Le Bon SD, Pisarski N, Verbeke J, Prunier L, Cavelier G, Thill MP, et al. Psychophysical evaluation of chemosensory functions 5 weeks after olfactory loss due to COVID-19: a prospective cohort study on 72 patients. Eur Arch Otorhinolaryngol. 2020;278:101-8.

12 Gunnell D, Appleby L, Arensman E, Hawton K, John A, Kapur N, et al. Suicide risk and prevention during the COVID-19 pandemic. Lancet Psychiatry. 2020;7:468-71.

13 Wang C, Pan R, Wan X, Tan Y, Xu L, McIntyre RS, et al. A longitudinal study on the mental health of general population during the COVID-19 epidemic in China. Brain Behav Immun. 2020;87:40-8.

14 Mazza MG, De Lorenzo R, Conte C, Poletti S, Vai B, Bollettini I, et al. Anxiety and depression in COVID-19 survivors: role of inflammatory and clinical predictors. Brain Behav Immun. 2020;89: 594-600.

15 Wu Y, Xu X, Chen Z, Duan J, Hashimoto K, Yang L, et al. Nervous system involvement after infection with COVID-19 and other coronaviruses. Brain Behav Immun. 2020;87:18-22.

16 Hakulinen C, Pulkki-Raback L, Virtanen M, Jokela M, Kivimaki M, Elovainio M. Social isolation and loneliness as risk factors for myocardial infarction, stroke and mortality: UK Biobank cohort study of 479054 men and women. Heart. 2018;104:1536-42.

17 Usher K, Bhullar N, Jackson D. Life in the pandemic: social isolation and mental health. J Clin Nurs. 2020;29:2756-7.

18 Levula A, Wilson A, Harré M. The association between social network factors and mental health at different life stages. Qual Life Res. 2016;25:1725-33.

19 Silva M, Resurrección DM, Antunes A, Frasquilho D, Cardoso G. Impact of economic crises on mental health care: a systematic review. Epidemiol Psychiatr Sci. 2018;29:e7.

20 Merzagora I, Mugellini G, Amadasi A, Travaini G. Suicide risk and the economic crisis: an exploratory analysis of the case of Milan. PloS One. 2016;11:e0166244.

$21 \mathrm{Siu}$ JY. The SARS-associated stigma of SARS victims in the postSARS era of Hong Kong. Qual Health Res. 2008;18:729-38.

22 Forlenza OV, Stella F, LIM-27 Psychogeriatric Clinic HCFMUSP. Impact of SARS-CoV-2 pandemic on mental health in the elderly: perspective from a psychogeriatric clinic at a tertiary hospital in São Paulo, Brazil. Int Psychogeriatr. 2020;32:1147-51.

23 Taylor WD, Blackford JU. Mental health treatment for front-line clinicians during and after the coronavirus disease 2019 (COVID-19) pandemic: a plea to the medical community. Ann Intern Med. 2020; 173:574-5.

24 Fukuti P, Uchôa CL, Mazzoco MF, Corchs F, Kamitsuji CS, De Rossi $L$, et al. How institutions can protect the mental health and psychosocial well-being of their healthcare workers in the current COVID-19 pandemic. Clinics (Sao Paulo). 2020;75:e1963.

25 Galea S, Merchant RM, Lurie N. The mental health consequences of COVID-19 and physical distancing: the need for prevention and early intervention. JAMA Intern Med. 2020;180:817-8.

26 DePierro J, Lowe S, Katz C. Lessons learned from 9/11: mental health perspectives on the COVID-19 pandemic. Psychiat Res. 2020;288:113024.

27 Liberati A, Altman DG, Tetzlaff J, Mulrow C, Gøtzsche PC, loannidis JP, et al. The PRISMA statement for reporting systematic reviews 
and meta-analyses of studies that evaluate healthcare interventions: explanation and elaboration. BMJ. 2009;339:b2700.

28 Moher D, Liberati A, Tetzlaff J, Altman DG PRISMA Group. Preferred reporting items for systematic reviews and meta-analyses: the PRISMA statement. PLoS Med. 2009;6:e1000097.

29 National Institute for Health Research (NIHR), PROSPERO. PROSPERO is fast-tracking registration of protocols related to COVID-19 [Internet]. 2020 [cited 2021 Jan 19]. www.crd.york.ac.uk/ prospero/

30 Berger VW, Alperson SY. A general framework for the evaluation of clinical trial quality. Rev Recent Clin Trials. 2009;4:79-88.

31 Goodman-Casanova JM, Dura-Perez E, Guzman-Parra J, CuestaVargas A, Mayoral-Cleries F. Telehealth home support during COVID-19 confinement for community-dwelling older adults with mild cognitive impairment or mild dementia: survey study. J Med Internet Res. 2020;22:e19434.

32 Liu K, Chen Y, Wu D, Lin R, Wang Z, Pan L. Effects of progressive muscle relaxation on anxiety and sleep quality in patients with COVID-19. Complement Ther Clin Pract. 2020;39:101132.

$33 \mathrm{Ng} \mathrm{SM}$, Chan TH, Chan CL, Lee AM, Yau JK, Chan CH, et al. Group debriefing for people with chronic diseases during the SARS pandemic: Strength-Focused and Meaning-Oriented Approach for Resilience and Transformation (SMART). Community Ment Health J. 2006;42:53-63

34 Wei N, Huang BC, Lu SJ, Hu JB, Zhou XY, Hu CC, et al. Efficacy of internet-based integrated intervention on depression and anxiety symptoms in patients with COVID-19. J Zhejiang Univ Sci B. 2020; 21:400-4.

35 Ghebreyesus TA. Addressing mental health needs: an integral part of COVID-19 response. World Psychiatry. 2020;19:129-30.

36 Agyapong VI. Coronavirus disease 2019 pandemic: health system and community response to a text message (Text4Hope) program supporting mental health in Alberta. Disaster Med Public Health Prep. 2020;14:e5-6.

37 Ahmadi A, Ghafour I, Hosseini SH, Hashemvarzi M. Psychological interventions for COVID-19 outbreak in Mazandaran province, Iran. Arch Clin Infect Dis. 2020;15:e103415.

38 Ahmed MZ, Ahmed O, Aibao Z, Hanbin S, Siyu L, Ahmad A. Epidemic of COVID-19 in China and associated psychological problems. Asian J Psychiatr. 2020;51:102092.

39 Albott CS, Wozniak JR, McGlinch BP, Wall MH, Gold BS, Vinogradov S. Battle Buddies: rapid deployment of a psychological resilience intervention for health care workers during the COVID-19 pandemic. Anesth Analg. 2020;131:43-54.

40 Altena E, Baglioni C, Espie CA, Ellis J, Gavriloff D, Holzinger B, et al. Dealing with sleep problems during home confinement due to the COVID-19 outbreak: practical recommendations from a task force of the european cbt-i academy. J Sleep Res. 2020;29:e13052.

41 Assari S, Habibzadeh P. The COVID-19 emergency response should include a mental health component. Arch Iran Med. 2020;23:281-2.

42 Balasubramanian A, Paleri V, Bennett R, Paleri V. Impact of COVID19 on the mental health of surgeons and coping strategies. Head Neck. 2020;42:1638-44.

43 Bao Y, Sun Y, Meng S, Shi J, Lu L. 2019-nCoV epidemic: address mental health care to empower society. Lancet. 2020;395:e37-8.

44 Bauerle A, Graf J, Jansen C, Dorrie N, Junne F, Teufel M, et al. An e-mental health intervention to support burdened people in times of the COVID-19 pandemic: CoPE It. J Public Health (Oxf). 2020;42: 647-8.

45 Bauerle A, Skoda EM, Dorrie N, Bottcher J, Teufel M. Psychological support in times of COVID-19: the Essen community-based CoPE concept. J Public Health (Oxf). 2020;42:649-50.

46 Behan $\mathrm{C}$. The benefits of meditation and mindfulness practices during times of crisis such as COVID-19. Ir J Psychol Med. 2020;37:256-8.

47 Bilal, Latif F, Bashir MF, Komal B, Tan D. Role of electronic media in mitigating the psychological impacts of novel coronavirus (COVID19). Psychiatry Res. 2020;289:113041

48 Billings J, Greene T, Kember T, Grey N, El-Leithy S, Lee D, et al. Supporting hospital staff during COVID-19: Early Interventions. Occup Med (Lond). 2020;70:327-9.

49 Blake $H$, Bermingham $F$, Johnson G, Tabner A. Mitigating the psychological impact of covid-19 on healthcare workers: a digital learning package. Int J Environ Res Public Health. 2020;17:2997.
50 Braus M, Morton B. Art therapy in the time of COVID-19. Psychol Trauma. 2020;12:S267-8.

51 Brawner BM. \#SendHelpNow: mental wellness and virtual connection in the age of coronavirus. J Psychiatr Ment Health Nurs. 2021; 28:121-2.

52 Cai H, Tu B, Ma J, Chen L, Fu L, Jiang Y, et al. Psychological impact and coping strategies of frontline medical staff in hunan between January and March 2020 during the outbreak of coronavirus disease 2019 (COVID19) in Hubei, China. Med Sci Monit. 2020;26:e924171.

53 Caroppo E, Lega I, Cognetti D, Rotunno V. Community mental health care in the COVID-19 response: an Italian example. Prim Care Companion CNS Disord. 2020;22:20com02659.

54 Caulfield KA, George MS. Treating the mental health effects of COVID-19: The need for at-home neurotherapeutics is now. Brain Stimul. 2020;13:939-40.

55 Chen Q, Liang M, Li Y, Guo J, Fei D, Wang L, et al. Mental health care for medical staff in China during the COVID-19 outbreak. Lancet Psychiatry. 2020;7:e15-6.

56 Chen S. An online solution focused brief therapy for adolescent anxiety during the novel coronavirus disease (COVID-19) pandemic: a structured summary of a study protocol for a randomised controlled trial. Trials. 2020;21:402.

57 Cheng P, Xia G, Pang P, Wu B, Jiang W, Li YT, et al. Covid-19 epidemic peer support and crisis intervention via social media. Community Ment Health J. 2020;56:786-92.

58 Chew QH, Wei KC, Vasoo S, Chua HC, Sim K. Narrative synthesis of psychological and coping responses towards emerging infectious disease outbreaks in the general population: practical considerations for the COVID-19 pandemic. Singapore Med J. 2020; 61:350-6.

59 Cole CL, Waterman S, Stott J, Saunders R, Buckman JE, Pilling S, et al. Adapting IAPT services to support frontline NHS staff during the Covid-19 pandemic: the Homerton Covid Psychological Support (HCPS) pathway. Cogn Behav Therap. 2020;13:e12.

60 Conejero I, Berrouiguet S, Ducasse D, Leboyer M, Jardon V, Olie E, et al. [Suicidal behavior in light of COVID-19 outbreak: Clinical challenges and treatment perspectives]. Encephale. 2020; 46:S66-72.

61 Courtet P, Olie E, Debien C, Vaiva G. Keep socially (but not physically) connected and carry on: preventing suicide in the age of COVID-19. J Clin Psychiatry. 2020;81:20com13370.

62 Dalton L, Rapa E, Stein A. Protecting the psychological health of children through effective communication about COVID-19. Lancet Child Adolesc Health. 2020;4:346-7.

63 de Girolamo G, Cerveri G, Clerici M, Monzani E, Spinogatti F, Starace F, et al. Mental health in the coronavirus disease 2019 emergency-the Italian response. JAMA Psychiatry. 2020;77:974-6.

64 De Sousa A, Mohandas E, Javed A. Psychological interventions during COVID-19: challenges for low and middle income countries. Asian J Psychiatr. 2020;51:102128.

65 Di Giuseppe M, Gemignani A, Conversano C. Psychological resources against the traumatic experience of COVID-19. Clin Neuropsychiatry. 2020;17:85-7.

66 Dickerson D. Seven tips to manage your mental health and wellbeing during the COVID-19 outbreak. Nature. 2020 Mar 26. doi:10. 1038/d41586-020-00933-5. Online ahead of print.

67 Duan L, Zhu G. Psychological interventions for people affected by the COVID-19 epidemic. Lancet Psychiatry. 2020;7:300-2.

68 Fearon P. Opening up while locking down: how an Irish independent sector mental health service is responding to the COVID-19 crisis Ir J Psychol Med. 2020;37:172-7.

69 Feng F, Tuchman S, Denninger JW, Fricchione GL, Yeung A. Qigong for the prevention, treatment, and rehabilitation of COVID-19 infection in older adults. Am J Geriatr Psychiatry. 2020;28:812-9.

70 Fineberg NA, Van Ameringen M, Drummond L, Hollander E, Stein DJ, Geller D, et al. How to manage obsessive-compulsive disorder (OCD) under COVID-19: a clinician's guide from the International College of Obsessive Compulsive Spectrum Disorders (ICOCS) and the Obsessive-Compulsive and Related Disorders Research Network (OCRN) of the European College of Neuropsychopharmacology. Compr Psychiatry. 2020;100:152174.

71 Ganesh A, Sahu P, Nair S, Chand P. A smartphone based e-consult in addiction medicine: an initiative in COVID lockdown. Asian J Psychiatr. 2020;51:102120. 
72 Gavin B, Hayden J, Adamis D, McNicholas F. Caring for the psychological well-being of healthcare professionals in the Covid-19 pandemic crisis. Ir Med J. 2020;113:51.

73 Greenberg N, Brooks SK, Wessely S, Tracy DK. How might the NHS protect the mental health of health-care workers after the COVID-19 crisis? Lancet Psychiatry. 2020;7:733-4.

74 Greenberg N, Docherty M, Gnanapragasam S, Wessely S. Managing mental health challenges faced by healthcare workers during covid-19 pandemic. BMJ. 2020;368:m1211.

75 Hiremath P, Suhas Kowshik CS, Manjunath M, Shettar M. COVID 19: Impact of lock-down on mental health and tips to overcome. Asian J Psychiatr. 2020;51:102088.

76 Ho CS, Chee CY, Ho RC. Mental health strategies to combat the psychological impact of COVID-19 beyond paranoia and panic. Ann Acad Med Singap. 2020;49:155-60.

$77 \mathrm{Hu} \mathrm{N}$, Mao H. Emergency management of mental hospitals during the outbreak of COVID-19. Psychiatry Investig. 2020;17:489-90.

$78 \mathrm{Hu}$ N, Pan S, Sun J, Wang Z, Mao H. Mental health treatment online during the COVID-19 outbreak. Eur Arch Psychiatry Clin Neurosci. 2020;270:783-4.

79 Huang J, Liu F, Teng Z, Chen J, Zhao J, Wang X, et al. Care for the psychological status of frontline medical staff fighting against Coronavirus Disease 2019 (COVID-19). Clin Infect Dis. 2020;71:3268-9.

80 Huang JW, Zhou XY, Lu SJ, Xu Y, Hu JB, Huang ML, et al. Dialectical behavior therapy-based psychological intervention for woman in late pregnancy and early postpartum suffering from COVID-19: a case report. J Zhejiang Univ Sci B. 2020;21:394-9.

81 Ifdil I, Fadli RP, Suranata K, Zola N, Ardi Z. Online mental health services in Indonesia during the COVID-19 outbreak. Asian J Psychiatr. 2020;51:102153

82 Inchausti F, MacBeth A, Hasson-Ohayon I, Dimaggio G. Psychological intervention and COVID-19: what we know so far and what we can do. J Contemp Psychother. 2020;1-8.

83 Jiang X, Deng L, Zhu Y, Ji H, Tao L, Liu L, et al. Psychological crisis intervention during the outbreak period of new coronavirus pneumonia from experience in Shanghai. Psychiatry Res. 2020;286: 112903.

84 Jung SJ, Jun JY. Mental health and psychological intervention amid COVID-19 outbreak: perspectives from South Korea. Yonsei Med J. 2020;61:271-2.

85 King JA, Cabarkapa S, Leow $\mathrm{FH}, \mathrm{Ng} \mathrm{CH}$. Addressing international student mental health during COVID-19: an imperative overdue. Australas Psychiatry. 2020;28:469.

86 Kiraly O, Potenza MN, Stein DJ, King DL, Hodgins DC, Saunders JB, et al. Preventing problematic internet use during the COVID-19 pandemic: Consensus guidance. Compr Psychiatry. 2020;100:152180.

87 Kisely S, Warren N, McMahon L, Dalais C, Henry I, Siskind D. Occurrence, prevention, and management of the psychological effects of emerging virus outbreaks on healthcare workers: rapid review and meta-analysis. BMJ. 2020;369:m1642.

88 Klomek AB. Suicide prevention during the COVID-19 outbreak. Lancet Psychiatry. 2020;7:390.

89 Kothari R, Forrester A, Greenberg N, Sarkissian N, Tracy DK. COVID-19 and prisons: providing mental health care for people in prison, minimising moral injury and psychological distress in mental health staff. Med Sci Law. 2020;60:165-8.

90 Kuzman MR, Curkovic M, Wasserman D. Principles of mental health care during the COVID-19 pandemic. Eur Psychiatry. 2020;63:e45.

91 Lapid MI, Koopmans R, Sampson EL, Van den Block L, Peisah C. Providing quality end-of-life care to older people in the era of COVID-19: perspectives from five countries. Int Psychogeriatr. 2020;32:1345-52.

92 Li S, Zhang Y. Mental healthcare for psychiatric inpatients during the COVID-19 epidemic. Gen Psychiatr. 2020;33:e100216.

93 Li W, Yang Y, Liu ZH, Zhao YJ, Zhang Q, Zhan L, et al. Progression of mental health services during the COVID-19 outbreak in China. Int J Biol Sci. 2020;16:1732-8.

94 Liu K. How I faced my coronavirus anxiety. Science. 2020;367:1398.

95 Liu S, Yang L, Zhang C, Xiang YT, Liu Z, Hu S, et al. Online mental health services in China during the COVID-19 outbreak. Lancet Psychiatry. 2020;7:e17-8.

96 Maben J, Bridges J. Covid-19: supporting nurses' psychological and mental health. J Clin Nurs. 2020;29:2742-50.
97 Mackolil J, Mackolil J. Addressing psychosocial problems associated with the COVID-19 lockdown. Asian J Psychiatr. 2020;51: 102156.

98 Manjunatha N, Kumar CN, Math SB. Coronavirus disease 2019 pandemic: time to optimize the potential of telepsychiatric aftercare clinic to ensure the continuity of care. Indian J Psychiatry. 2020;62: 320-1.

99 Marazziti D. The COVID-19 outbreak: the latest challenge to psychological and psychiatric intervention. Clin Neuropsychiatry. 2020; 17:39-40.

100 Marcinko D, Jakovljevic M, Jaksic N, Bjedov S, Mindoljevic Drakulic A. The importance of psychodynamic approach during COVID-19 pandemic. Psychiatr Danub. 2020;32:15-21.

101 Marques L, Bartuska AD, Cohen JN, Youn SJ. Three steps to flatten the mental health need curve amid the COVID-19 pandemic. Depress Anxiety. 2020;37:405-6.

102 Matthewson J, Tiplady A, Gerakios F, Foley A, Murphy E. Implementation and analysis of a telephone support service during COVID-19. Occup Med (Lond). 2020;70:375-81.

103 Mclntyre RS, Lee Y. Preventing suicide in the context of the COVID19 pandemic. World Psychiatry. 2020;19:250-1.

104 Mediavilla R, Fernandez-Jimenez E, Rodriguez-Vega B, GotorMartinez L, Rivelles-Sevilla RV, Rojano-Capilla P, et al. Adapting mental health care after the COVID-19 outbreak: Preliminary findings from a public general hospital in Madrid (Spain). Psychiatry Res. 2020;289:113077.

105 Moesmann Madsen M, Dines D, Hieronymus F. Optimizing psychiatric care during the COVID-19 pandemic. Acta Psychiatr Scand. 2020;142:70-1.

106 Moghanibashi-Mansourieh A. Assessing the anxiety level of Iranian general population during COVID-19 outbreak. Asian J Psychiatr. 2020;51:102076

107 Monteith LL, Holliday R, Brown TL, Brenner LA, Mohatt NV. Preventing suicide in rural communities during the COVID-19 pandemic. J Rural Health. 2021;37:179-84.

108 Moring JC, Dondanville KA, Fina BA, Hassija C, Chard K, Monson $\mathrm{C}$, et al. Cognitive processing therapy for posttraumatic stress disorder via telehealth: practical considerations during the COVID-19 pandemic. J Trauma Stress. 2020;33:371-9.

109 Mukhtar S. Mental health and psychosocial aspects of Coronavirus outbreak in Pakistan: psychological intervention for public mental health crisis. Asian J Psychiatr. 2020;51:102069.

110 Nguyen HC, Nguyen MH, Do BN, Tran CQ, Nguyen TTP, Pham KM, et al. People with suspected COVID-19 symptoms were more likely depressed and had lower health-related quality of life: the potential benefit of health literacy. J Clin Med. 2020;9:965.

111 O'Donoghue B, O'Connor K, Thompson A, McGorry P. The need for early intervention for psychosis to persist throughout the COVID-19 pandemic and beyond. Ir J Psychol Med. 2020;1-6.

112 Orru' G, Ciacchini R, Gemignani A, Conversano C. Psychological intervention measures during the COVID-19 pandemic. Clin Neuropsychiatry. 2020;17:76-9.

113 Park SC, Park YC. Mental health care measures in response to the 2019 novel Coronavirus outbreak in Korea. Psychiatry Investig. 2020;17:85-6.

114 Patel V. Empowering global mental health in the time of Covid19. Asian J Psychiatr. 2020;51:102160.

115 Peitl V, Zatezalo VG, Karlović D. Mental health issues and psychological crisis interventions during the COVID-19 pandemic and earthquakes in Croatia. Arch Psychiatr Res. 2020;56:193-8.

116 Percudani M, Corradin M, Moreno M, Indelicato A, Vita A. Mental health services in Lombardy during COVID-19 outbreak. Psychiatry Res. 2020;288:112980.

117 Petzold MB, Plag J, Strohle A. [Dealing with psychological distress by healthcare professionals during the COVID-19 pandemia]. Nervenarzt. 2020;91:417-21.

118 Ping NP, Shoesmith WD, James S, Nor Hadi NM, Yau EK, Lin LJ. Ultra brief psychological interventions for COVID-19 pandemic: introduction of a locally-adapted brief intervention for mental health and psychosocial support service. Malays J Med Sci. 2020; 27:51-6.

119 Ransing R, Adiukwu F, Pereira-Sanchez V, Ramalho R, Orsolini L, Teixeira AL, et al. Mental health interventions during the COVID-19 
pandemic: a conceptual framework by early career psychiatrists. Asian J Psychiatr. 2020;51:102085.

120 Renjun G, Ziyun L, Xiwu Y, Wei W, Yihuang G, Chunbing Z, et al. Psychological intervention on COVID-19: a protocol for systematic review and meta-analysis. Medicine (Baltimore). 2020;99:e20335.

121 Restauri N, Sheridan AD. Burnout and posttraumatic stress disorder in the coronavirus disease 2019 (COVID-19) pandemic: intersection, impact, and interventions. J Am Coll Radiol. 2020;17:921-6.

122 Roycroft M, Wilkes D, Fleming S, Pattani S, Olsson-Brown A. Preventing psychological injury during the COVID-19 pandemic. BMJ. 2020;369:m1702.

123 Santarone K, McKenney M, Elkbuli A. Preserving mental health and resilience in frontline healthcare workers during COVID-19. Am J Emerg Med. 2020;38:1530-1.

124 Shanafelt T, Ripp J, Trockel M. Understanding and addressing sources of anxiety among health care professionals during the COVID-19 pandemic. JAMA. 2020;323:2133-4.

125 Shi W, Hall BJ. What can we do for people exposed to multiple traumatic events during the coronavirus pandemic? Asian J Psychiatr. 2020;51:102065.

126 Sun QH, Su Y. Psychological crisis intervention for college students during novel coronavirus infection epidemic. Psychiatry Res. 2020; 289:113043.

127 Sun Y, Bao Y, Lu L. Addressing mental health care for the bereaved during the COVID-19 pandemic. Psychiatry Clin Neurosci. 2020;74: 406-7.

128 Talidong KJB, Toquero CMD. Philippine teachers' practices to deal with anxiety amid COVID-19. J Loss Trauma. 2020;25:573-9.

129 Tracy DK, Tarn M, Eldridge R, Cooke J, Calder JD, Greenberg N. What should be done to support the mental health of healthcare staff treating COVID-19 patients? Br J Psychiatry. 2020;217:537-9.

130 Wasserman $D$, van der Gaag R, Wise J. The term 'physical distancing' is recommended rather than 'social distancing' during the COVID-19 pandemic for reducing feelings of rejection among people with mental health problems. Eur Psychiatry. 2020;63:e52.

131 Weerkamp-Bartholomeus P, Marazziti D, van Amelsvoort T. WARA (wiring affect with reattach) provided by remote training: first-aid psychological intervention? Clin Neuropsychiatry. 2020;17.

$132 \mathrm{Wu}$ K, Wei X. Analysis of psychological and sleep status and exercise rehabilitation of front-line clinical staff in the fight against COVID-19 in China. Med Sci Monit Basic Res. 2020;26:e924085.

$133 \mathrm{Wu}$ PE, Styra R, Gold WL. Mitigating the psychological effects of COVID-19 on health care workers. CMAJ. 2020;192:E459-60.

134 Xiang YT, Zhao YJ, Liu ZH, Li XH, Zhao N, Cheung T, et al. The COVID-19 outbreak and psychiatric hospitals in China: managing challenges through mental health service reform. Int $\mathrm{J}$ Biol Sci. 2020;16:1741-4.

135 Xiao H, Zhang Y, Kong D, Li S, Yang N. The effects of social support on sleep quality of medical staff treating patients with Coronavirus disease 2019 (COVID-19) in January and February 2020 in China. Med Sci Monit. 2020;26:e923549.

136 Yang J, Tong J, Meng F, Feng Q, Ma H, Shi C, et al. Characteristics and challenges of psychological first aid in China during the COVID19 outbreak. Brain Behav Immun. 2020;87:113-4.

137 Yang L, Yin J, Wang D, Rahman A, Li X. Urgent need to develop evidence-based self-help interventions for mental health of healthcare workers in COVID-19 pandemic. Psychol Med. 2020 Apr 28; 1-2. doi:10.1017/S0033291720001385. Online ahead of print.

138 Yin Q, Sun Z, Liu T, Ni X, Deng X, Jia Y, et al. Posttraumatic stress symptoms of health care workers during the corona virus disease 2019. Clin Psychol Psychother. 2020;27:384-95.

139 Zaka A, Shamloo SE, Fiorente P, Tafuri A. COVID-19 pandemic as a watershed moment: a call for systematic psychological health care for frontline medical staff. J Health Psychol. 2020;25:883-7.

140 Zhai Y, Du X. Mental health care for international Chinese students affected by the COVID-19 outbreak. Lancet Psychiatry. 2020;7:e22

141 Zhai Y, Du X. Addressing collegiate mental health amid COVID-19 pandemic. Psychiatry Res. 2020;288:113003.

142 Zhang J, Wu W, Zhao X, Zhang W. Recommended psychological crisis intervention response to the 2019 novel coronavirus pneumonia outbreak in China: a model of West China Hospital. Precis Clin Med. 2020 Feb 18;pbaa006. Published online 2020 Feb 18. doi: $10.1093 /$ pcmedi/pbaa006
143 Zhang $\mathrm{Y}$, Zhang H, Ma X, Di Q. Mental health problems during the COVID-19 pandemics and the mitigation effects of exercise: a longitudinal study of college students in China. Int $\mathrm{J}$ Environ Res Public Health. 2020;17.

144 Zhou X. Psychological crisis interventions in Sichuan Province during the 2019 novel coronavirus outbreak. Psychiatry Res. 2020;286:112895

145 Zhou X, Snoswell CL, Harding LE, Bambling M, Edirippulige S, Bai $\mathrm{X}$, et al. The role of telehealth in reducing the mental health burden from COVID-19. Telemed J E Health. 2020;26:377-9.

146 Chan AO, Huak CY. Psychological impact of the 2003 severe acute respiratory syndrome outbreak on health care workers in a medium size regional general hospital in Singapore. Occup Med (Lond). 2004;54:190-6.

147 Chen R, Chou KR, Huang YJ, Wang TS, Liu SY, Ho LY. Effects of a SARS prevention programme in Taiwan on nursing staff's anxiety, depression and sleep quality: a longitudinal survey. Int J Nurs Stud. 2006;43:215-25

148 Cheng SK, Wong CW. Psychological intervention with sufferers from severe acute respiratory syndrome (SARS): lessons learnt from empirical findings. Clin Psychol Psychoter. 2005;12:80-6.

149 Mak IW. Delivering psychiatric care for patients recovering from massive infectious disease outbreak - moving on from SARS to Post-SARS Era. East Asian Arch Psychiatry. 2010;20:16-7.

150 Mak WW, Law RW, Woo J, Cheung FM, Lee D. Social support and psychological adjustment to SARS: the mediating role of self-care self-efficacy. Psychol Health. 2009;24:161-74.

151 Xiao R, Wang HQ, Shi HM, Li L, Xie XS, Liu XQ. Relation between social support and mental health of patients with severe acute respiratory syndrome. Chin J Clin Rehabil. 2004;8:3474-5.

152 Yoon MK, Kim SY, Ko HS, Lee MS. System effectiveness of detection, brief intervention and refer to treatment for the people with post-traumatic emotional distress by MERS: a case report of community-based proactive intervention in South Korea. Int J Ment Health Syst. 2016;10:51.

153 Wang Z, Zhu Z, Zhu H. Psychological crisis intervention model in Xiaotangshan Hospital of PLA. CMHJ. 2002;9.

154 Bryant RA. Acute stress disorder as a predictor of posttraumatic stress disorder: a systematic review. J Clin Psychiatry. 2011;72: 233-9.

155 Birur B, Moore NC, Davis LL. An evidence-based review of early intervention and prevention of posttraumatic stress disorder. Community Ment Health J. 2017;53:183-201.

156 Dutheil F, Mondillon L, Navel V. PTSD as the second tsunami of the SARS-Cov2 pandemic. Psychol Med. 2020 Apr 24;1-2. doi:10.1017/ S0033291720001336. Online ahead of print.

157 Xu J, Zheng Y, Wang M, Zhao J, Zhan Q, Fu M, et al. Predictors of symptoms of posttraumatic stress in Chinese university students during the 2009 H1N1 influenza pandemic. Med Sci Monit. 2011;17: PH60-4.

158 Ribeiro MR, Damiano RF, Marujo R, Nasri F, Lucchetti G. The role of spirituality in the COVID-19 pandemic: a spiritual hotline project J Public Health (Oxf). 2020;42:855-6.

159 Ursano RJ, Bell C, Eth S, Friedman M, Norwood A, Pfefferbaum B, et al. Practice guideline for the treatment of patients with acute stress disorder and posttraumatic stress disorder. Am J Psychiatry 2004;161(11 Suppl):3-31.

160 Bryant RA. The current evidence for acute stress disorder. Curr Psychiatry Rep. 2018;20:111.

161 Cohen JA, Mannarino AP. Trauma-focused cognitive behavior therapy for traumatized children and families. Child Adolesc Psychiatr Clin N Am. 2015;24:557-70.

162 Rothbaum BO, Kearns MC, Price M, Malcoun E, Davis M, Ressler $\mathrm{KR}$, et al. Early intervention may prevent the development of posttraumatic stress disorder: a randomized pilot civilian study with modified prolonged exposure. Biol Psychiatry. 2012;72:957-63.

163 Shalev AY, Ankri Y, Israeli-Shalev Y, Peleg T, Adessky R, Freedman S. Prevention of posttraumatic stress disorder by early treatment: results from the Jerusalem trauma outreach and prevention study. Arch Gen Psychiatry. 2012;69:166-76.

164 Rose S, Bisson J, Churchill R, Wessely S. Psychological debriefing for preventing post traumatic stress disorder (PTSD). Cochrane Database Syst Rev. 2002(2):CD000560. 
165 Mellman TA, Bustamante V, David D, Fins Al. Hypnotic medication in the aftermath of trauma. J Clin Psychiatry. 2002;63:1183-4.

166 Gelpin E, Bonne O, Peri T, Brandes D, Shalev AY. Treatment of recent trauma survivors with benzodiazepines: a prospective study. J Clin Psychiatry. 1996;57:390-4.

167 Guina J, Rossetter SR, DeRhodes BJ, Nahhas RW, Welton RS. Benzodiazepines for PTSD: a systematic review and meta-analysis. J Psychiatr Pract. 2015;21:281-303.

168 Arias AJ, Steinberg K, Banga A, Trestman RL. Systematic review of the efficacy of meditation techniques as treatments for medical illness. J Altern Complement Med. 2006;12:817-32.

169 Hoge EA, Bui E, Palitz SA, Schwarz NR, Owens ME, Johnston JM, et al. The effect of mindfulness meditation training on biological acute stress responses in generalized anxiety disorder. Psychiatry Res. 2018;262:328-32.

170 Gotink RA, Meijboom R, Vernooij MW, Smits M, Hunink MG. 8-week mindfulness based stress reduction induces brain changes similar to traditional long-term meditation practice - a systematic review. Brain Cogn. 2016;108:32-41.

171 Moss AS, Wintering N, Roggenkamp H, Khalsa DS, Waldman MR Monti D, et al. Effects of an 8-week meditation program on mood and anxiety in patients with memory loss. J Altern Complement Med. 2012;18:48-53.

172 Farias M, Maraldi E, Wallenkampf KC, Lucchetti G. Adverse events in meditation practices and meditation-based therapies: a systematic review. Acta Psychiatr Scand. 2020;142:374-93.

173 Posluns K, Gall TL. Dear mental health practitioners, take care of yourselves: a literature review on self-care. Int J Adv Couns. 2020; 42:1-20.

174 Lucock M, Gillard S, Adams K, Simons L, White R, Edwards C. Selfcare in mental health services: a narrative review. Health Soc Care Comm. 2011;19:602-16.

175 Harvey SB, Øverland S, Hatch SL, Wessely S, Mykletun A, Hotopf $M$. Exercise and the prevention of depression: results of the HUNT cohort study. Am J Psychiatry. 2018;175:28-36.

176 Schwartz C, Meisenhelder JB, Ma Y, Reed G. Altruistic social interest behaviors are associated with better mental health. Psychosom Med. 2003;65:778-85

177 Feng Y, Zong M, Yang Z, Gu W, Dong D, Qiao Z. When altruists cannot help: the influence of altruism on the mental health of university students during the COVID-19 pandemic. Global Health. 2020;16:61.
178 Fujiwara T. The role of altruistic behavior in generalized anxiety disorder and major depression among adults in the United States J Affect Disord. 2007;101:219-25.

179 Fisk M, Livingstone A, Pit SW. Telehealth in the context of COVID19: changing perspectives in Australia, the United Kingdom, and the United States. J Med Internet Res. 2020;22:e19264.

180 Kross E, Verduyn P, Demiralp E, Park J, Lee DS, Lin N, et al. Facebook use predicts declines in subjective well-being in young adults. PloS One. 2013;8:e69841.

181 Demirci K, Akgonul M, Akpinar A. Relationship of smartphone use severity with sleep quality, depression, and anxiety in university students. J Behav Addict. 2015;4:85-92.

182 Bessière K, Pressman S, Kiesler S, Kraut R. Effects of internet use on health and depression: a longitudinal study. J Med Internet Res. 2010;12:e6.

183 Autrán-Gómez AM, Favorito LA. The social, economic and sanitary impact of COVID-19 pandemic. Int Braz J Urol. 2020;46(Suppl1): 3-5.

184 Frasquilho D, Matos MG, Salonna F, Guerreiro D, Storti CC, Gaspar $\mathrm{T}$, et al. Mental health outcomes in times of economic recession: a systematic literature review. BMC Public Health. 2016;16:115

185 Danielli S, Patria R, Donnelly P, Ashrafian H, Darzi A. Economic interventions to ameliorate the impact of COVID-19 on the economy and health: an international comparison. J Public Health (Oxf). 2020 Jul 13;fdaa104. doi:10.1093/pubmed/fdaa104. Online ahead of print.

186 Moreira-Almeida A, Koenig HG, Lucchetti G. Clinical implications of spirituality to mental health: review of evidence and practical guidelines. Braz J Psychiatry. 2014;36:176-82.

187 Koenig HG. Research on religion, spirituality, and mental health: a review. Can J Psychiatry. 2009;54:283-91.

188 del Castillo FA, Biana HT, Joaquin JJ. ChurchlnAction: the role of religious interventions in times of COVID-19. J Public Health (Oxf). 2020;42:633-4.

189 Rajeswari S, SanjeevaReddy N. Efficacy of progressive muscle relaxation on pregnancy outcome among anxious Indian primi mothers. Iran J Nurs Midwifery Res. 2020;25:23-30.

190 Metin ZG, Karadas C, Izgu N, Ozdemir L, Demirci U. Effects of progressive muscle relaxation and mindfulness meditation on fatigue, coping styles, and quality of life in early breast cancer patients: an assessor blinded, three-arm, randomized controlled trial. Eur J Oncol Nurs. 2019;42:116-25. 